\title{
Comparative role of non-stress test and colour doppler in high risk pregnancy predicted by placental histopathology and foetal outcome
}

\author{
Shruti Paliwal ${ }^{1}$, Rizwana Shaheen ${ }^{1}$, Shweta Paliwal' ${ }^{2}$, Poonam Parakh1, Kanchan Yadav', \\ Goury Chaudhary ${ }^{1}$, Jitendra Jalandhara ${ }^{1}$
}

${ }^{1}$ Department of Obstetrics and Gynaecology, Dr. Sampurnanand Medical College, Jodhpur, Rajasthan, India. ${ }^{2}$ Department of Obstetrics and Gynaecology, SAIMS Medical College, Indore, Madhya Pradesh, India

Received: 24 January 2017

Revised: 03 February 2017

Accepted: 02 March 2017

\section{*Correspondence:}

Dr. Shruti Paliwal,

E-mail: shrutipaliwal.paliwal@gmail.com

Copyright: (c) the author(s), publisher and licensee Medip Academy. This is an open-access article distributed under the terms of the Creative Commons Attribution Non-Commercial License, which permits unrestricted non-commercial use, distribution, and reproduction in any medium, provided the original work is properly cited.

\begin{abstract}
Background: Assessment of the foetal wellbeing is done by various biophysical methods. Non stress test (NST) is the most commonly used test for antepartum evaluation of foetal status. It involves the use of doppler-detected foetal heart rate acceleration coincident with foetal movement perceived by mother. Duplex sonography and its off-shoot, colour duplex sonography, are relatively newer methods that combine the pulsed echo technique of sectional image formation with the doppler evaluation of blood flow.

Methods: The comparative study was carried out on 200 booked term pregnant patients in the department of Obstetrics and Gynaecology, Dr. S. N. Medical College, Jodhpur Rajasthan, India. All patients were subjected to nonstress test and colour doppler and were evaluated for placental histopathology and foetal outcome in terms of low APGAR score, number of NICU admissions and perinatal mortality.

Results: In our study it was found that in high-risk group 25\% had non-reassuring NST and 19\% had doppler findings suggestive of foetal hypoxia. In the control group $13 \%$ had non-reassuring NST and $4 \%$ had doppler findings suggestive of foetal hypoxia. It was seen that when either NST was non-reassuring or colour doppler suggested foetal hypoxia or both, these patients required admissions antenatally, had meconium stained liquor suggestive of foetal distress, had operative delivery for foetal distress, had low APGAR score, required NICU admission, and higher perinatal mortality.

Conclusions: Doppler and NST are effective in predicting a normal healthy foetus. Doppler depicts chronic hypoxic changes while NST can detect acute events in presence or absence of chronic hypoxia.
\end{abstract}

Keywords: APGAR score, Colour doppler, Nonstress test, Placental histopathology

\section{INTRODUCTION}

The desire of every women contemplating motherhood is that her pregnancy culminates in a healthy offspring who will achieve the highest possible physical and mental potential. Assessment of the foetal wellbeing is done by various biophysical methods. Non stress test is the most commonly used test for antepartum evaluation of foetal status. It is easy, non-invasive, easily performed and interpreted method by which can identify nearly twice many foetus with an abnormal foetal heart rate pattern than intermittent auscultation of foetal heart rate. ${ }^{1}$ The non-stress test involves the use of doppler-detected foetal heart rate acceleration coincident with foetal movement perceived by mother By the end of 1970's NST had become the sole method of testing foetal health. At present NST is the most widely used and accepted method of antenatal foetal surveillance. It is based on 
hypothesis of intact neurologic coupling between foetal CNS and foetal heart. ${ }^{2}$

Duplex sonography and its off-shoot, Colour duplex sonography, are relatively new methods that combine the pulsed echo technique of sectional image formation with the Doppler evaluation of blood flow. It is based on Bmode ultrasound, which permits an accurate morphology of gynaecological and obstetrical findings as a result of increasingly higher resolution and faster frame rates. It is now widely used in clinical practice. Flow velocity waveforms of umbilical, uterine and middle cerebral artery have been used in numerous studies in detecting foetal compromise in high-risk pregnancies.

The doppler evaluation in obstetrics involves assessment of various vessels of foetus. Each has its own significance. In cases of preeclampsia, the uterine artery velocitimetry had a better predictive value than umbilical artery, with exception of cases that had IUGR. It is recommended to incorporate uterine artery and umbilical artery surveillance of pregnant women with diabetes with complication of vascular disease, IUGR or hypertension. ${ }^{3}$

\section{METHODS}

This present prospective study was conducted in department of obstetrics and Gynecology, Dr. S. N. Medical College Jodhpur, Rajasthan, India from period of November 2015 to October 2016. The study was done on 200 cases. 100 high risk cases were taken randomly as study group and 100 normal pregnancy cases were taken as control. As per the proforma a detailed history including the obstetric history, menstrual history and significant past and family history was taken.

\section{Inclusion criteria}

Colour doppler and NST study in pregnant women with singleton foetus at term with

- Hypertensive disorder of pregnancy like gestational hypertension, preeclampsia, eclampsia.

- Oligohydramnios: AFI $<5 \mathrm{~cm}$.

- Estimated foetal weight $<10^{\text {th }}$ percentile for gestation age.

- Gestational diabetes mellitus.

- Chronic renal disease

- Hypertension due to other causes vascular, endocrinal, neurogenic.

\section{Exclusion criteria}

- Severe malnutrition

- Mothers with foetus with symmetrical IUGR due to genetic causes and infection, chromosomal disorders occurring in 1 st trimester.

- Mothers with IUD foetus

- Mothers with foetus with congenital malformation
- Preterm foetus

- Patients not giving consent

- Those patients who came in labour with no ANC investigation.

All foetuses were categorized in four sub-groups according to their NST and Doppler findings:

- Group A- NST reassuring + colour Doppler normal

- Group B- NST non-reassuring+ colour Doppler normal

- Group C- NST reassuring+ colour Doppler foetal hypoxia

- Group D- NST non reassuring + colour Doppler foetal hypoxia

Among all 4 groups perinatal outcome was assessed by following parameter:

- Mode of delivery

- $\quad$ APGAR score at 0,1 and 5 minute

- Birth weight

- NICU admission

- NICU stay duration

- Neonatal morbidity/mortality

\section{RESULTS}

Mean age group of the study population was 24.5 years and of the control population was 23.9 years. $54 \%$ of the study population was primigravida and $45 \%$ of the control population was primigravida. Maximum number of patients in both study and control group were literate. Study population was $69 \%$ literate and control population was $75 \%$ literate (Table 1).

Table 1: Maternal characteristics of study and control population.

\begin{tabular}{|lll|}
\hline Maternal characteristics & $\begin{array}{l}\text { Study } \\
\text { group }\end{array}$ & $\begin{array}{l}\text { Control } \\
\text { group }\end{array}$ \\
\hline Mean age (years) & 24.5 & 23.9 \\
\hline Percentage of primigravida & $54 \%$ & $45 \%$ \\
\hline Percentage of literates & $69 \%$ & $75 \%$ \\
\hline
\end{tabular}

Table 2 and 3 show the pregnancy complications, mode of delivery and perinatal outcome in different subgroups. Group D which had both tests abnormal had the worst perinatal outcome.

Group A had best perinatal outcome. There were only $10 \%$ NICU admission in the group with reassuring NST and normal blood flow pattern in colour Doppler. In contrast $78.57 \%$ foetuses required antenatal admission when both NST was non-reassuring or colour Doppler showed hypoxia. $24.28 \%$ new borns were SGA when NST was reassuring and colour doppler showed normal blood flow pattern. Significantly higher proportions of infant were SGA when either NST was non-reassuring or 
colour doppler showed foetal hypoxia. Only $14.28 \%$ had operative delivery for foetal distress when NST was reassuring and colour doppler showed normal blood flow pattern. In contrast $78.57 \%$ infants had operative delivery for foetal distress when NST was non-reassuring or colour doppler showed foetal hypoxia. It was seen that APGAR score both at 1 and 5 min were lower in high risk group than control group.

Table 2: Group comparison in study population.

\begin{tabular}{|c|c|c|c|c|}
\hline Characteristic & Subgroup A & Subgroup B & Subgroup C & Subgroup D \\
\hline Gestation age at birth (in weeks) & $38.25(1.83)$ & $37.45(1.99)$ & $37.4(0.83)$ & $37.71(2.0)$ \\
\hline $\begin{array}{l}\text { Number and percentage of } \\
\text { patients requiring antenatal } \\
\text { admission }\end{array}$ & $7(10 \%)$ & $\begin{array}{l}6(54.55 \%) \\
(\text { OR-10.8, } \\
95 \% \text { CI-3.05-38.11) }\end{array}$ & $\begin{array}{l}4(80 \%) \\
(\mathrm{OR}-36, \\
95 \% \text { CI-7.17-180.56) }\end{array}$ & $\begin{array}{l}10(71.43 \%) \\
(\text { OR-22.5, } 95 \% \\
\text { CI-7.11-71.2) }\end{array}$ \\
\hline $\begin{array}{l}\text { Number and percentage of } \\
\text { patients with meconium stained } \\
\text { liquor }\end{array}$ & $7(10 \%)$ & $\begin{array}{l}9(81.82 \%) \\
(\text { OR-40.5, } \\
95 \% \text { CI-11.08-147) }\end{array}$ & $\begin{array}{l}4(80 \%)(\mathrm{OR}-36, \\
95 \% \text { CI-6.68-193.98) }\end{array}$ & $\begin{array}{l}10(71.42 \%)(\mathrm{OR}- \\
22.5,95 \% \mathrm{CI}- \\
6.89-73.45)\end{array}$ \\
\hline $\begin{array}{l}\text { Number and percentage of } \\
\text { patients who had operative } \\
\text { delivery for fetal distress }\end{array}$ & $10(14.28 \%)$ & $\begin{array}{l}5(45.45 \%) \\
(\mathrm{OR}-5, \\
95 \% \text { CI-1.37-18.11) }\end{array}$ & $2(40 \%)(\mathrm{NS})$ & $\begin{array}{l}11(78.57 \%)(\mathrm{OR}- \\
22,95 \% \mathrm{CI}-5.38- \\
75.75)\end{array}$ \\
\hline Mean placental weight (in grams) & $575.97(12.82)$ & $516.36(124.98)$ & $390(113.82)$ & $490(111.97)$ \\
\hline $\begin{array}{l}\text { Placenta with abnormal } \\
\text { histopathological finding }\end{array}$ & $28(40 \%)$ & $\begin{array}{l}9(81.81 \%) \\
(\text { OR-6.75, } \\
95 \% \text { CI } 1.55-29.36)\end{array}$ & $4(80 \%)$ & $14(100 \%)$ \\
\hline Number of SGA fetus & $17(24.28 \%)$ & $\begin{array}{l}7(63.63 \%) \\
\text { (OR-5.45, } \\
95 \% \text { CI-1.52-19.43) }\end{array}$ & $\begin{array}{l}4(80 \%) \\
(\mathrm{OR}-12.47 \\
95 \% \text { CI-1.93-80.68) }\end{array}$ & $\begin{array}{l}8(57.14 \%),(\mathrm{OR}- \\
4.15,95 \% \mathrm{CI} \\
1.32-13.14)\end{array}$ \\
\hline Mean fetal weight(in grams) & $\begin{array}{l}2797.91 \\
(533.4)\end{array}$ & $2307.27(564.51)$ & $2260(554.14)$ & $2342.86(548.13)$ \\
\hline Mean APGAR score at $1 \mathrm{~min}$ & $7.22(1.66)$ & $5.72(1.65)$ & $5(1.67)$ & $3.85(1.78)$ \\
\hline Number of NICU admissions & $7(10 \%)$ & $\begin{array}{l}6(54.54 \%) \\
(\mathrm{OR}-10.8 \\
95 \% \text { CI-3.05-38.11) }\end{array}$ & $\begin{array}{l}3(60 \%)(\mathrm{OR}-13.5 \\
95 \% \text { CI-2.61-69.57) }\end{array}$ & $\begin{array}{l}11(78.57 \%)(\mathrm{OR}- \\
32.58,95 \% \mathrm{CI}- \\
9.62-110.27)\end{array}$ \\
\hline Number of perinatal deaths & $1(1.43 \%)$ & $0(0 \%)(\mathrm{NS})$ & $\begin{array}{l}1(20 \%) \\
(\text { OR-17.25, } \\
95 \% \text { CI-1.76-168.35) }\end{array}$ & $\begin{array}{l}2(14.29 \%)(\mathrm{OR}- \\
11.5,95 \% \mathrm{CI}- \\
1.47-89.47)\end{array}$ \\
\hline
\end{tabular}

Table 3: Group comparison in control population.

\begin{tabular}{|c|c|c|c|c|}
\hline Characteristic & Subgroup A & Subgroup B & Subgroup C & Subgroup D \\
\hline Gestation age at birth(in weeks) & $38.92(2.24)$ & $39.7(2.30)$ & 40 & $38(1.29)$ \\
\hline $\begin{array}{l}\text { Number and percentage of patients } \\
\text { requiring antenatal admission }\end{array}$ & $6(6.98 \%)$ & $\begin{array}{l}5(50 \%) \\
\text { (OR-13.3 95\%CI-3.65- } \\
48.66)\end{array}$ & $1(100 \%)(\mathrm{NS})$ & $\begin{array}{l}2(66.67 \%) \\
(\text { OR-26.66, } \\
95 \% \text { CI-4.23-167) }\end{array}$ \\
\hline $\begin{array}{l}\text { Number and percentage of patients } \\
\text { with meconium stained liquor }\end{array}$ & $3(3.49 \%)$ & $\begin{array}{l}6(60 \%)(\mathrm{OR}-41.5 \\
95 \% \mathrm{CI}-11.69-147.29)\end{array}$ & $1(100 \%)(\mathrm{NS})$ & $3(100 \%)(\mathrm{NS})$ \\
\hline $\begin{array}{l}\text { Number and percentage of patients } \\
\text { who had operative delivery for } \\
\text { fetal distress }\end{array}$ & $9(10.47 \%)$ & $\begin{array}{l}4(40 \%)(\mathrm{OR}-11.4,95 \% \\
\text { CI-6.38-75.75) }\end{array}$ & $1(100 \%)(\mathrm{NS})$ & $3(100 \%)(\mathrm{NS})$ \\
\hline Mean placental weight(in grams) & $597.2(82.78)$ & $627(80.47)$ & 630 & $513.33(77.53)$ \\
\hline $\begin{array}{l}\text { Placenta with abnormal } \\
\text { histopathological finding }\end{array}$ & $7(8.13 \%)$ & $\begin{array}{l}7(70 \%)(\mathrm{OR}-27,95 \% \mathrm{CI}- \\
7.97-91.4)\end{array}$ & $1(100 \%)$ & $3(100 \%)$ \\
\hline Number of SGA foetus & $8(9.3 \%)$ & $1(10 \%)(\mathrm{NS})$ & $1(100 \%)(\mathrm{NS})$ & $3(100 \%)(\mathrm{NS})$ \\
\hline Mean fetal weight(in grams) & $2883.37(402.3)$ & $2980(401.77)$ & 3000 & $2933.33(324.82)$ \\
\hline Mean APGAR score at $1 \mathrm{~min}$ & $7.22(0.87)$ & $6.2(0.88)$ & 8 & $5.33(0.90)$ \\
\hline Number of NICU admissions & $2(2.32 \%)$ & $\begin{array}{l}7(70 \%) \text { (OR-96, 95\% } \\
\text { CI-25.55-360) }\end{array}$ & $1(100 \%)(\mathrm{NS})$ & $3(100 \%)([\mathrm{NS})$ \\
\hline
\end{tabular}

(Data in paranthesis is standard deviation from mean, OR- odd's ratio, 95\%CI- 95\% confidence interval, NS-not significant) 
The APGAR score when NST was non-reassuring and colour doppler showed hypoxia was lower (3.85) than when both were normal (7.22).

Table 4 shows the sensitivity, specificity, positive predictive value and negative predictive value of nonstress test and colour doppler.

Table 4: Sensitivity, specificity, positive predictive value and negative predictive value of NST and colour doppler in prediction of APGAR score $<7$ at 1 min.

\begin{tabular}{|lll|}
\hline Sensitivity & NST (\%) & Color Doppler (\%) \\
\hline Specificity & 60 & 47.2 \\
\hline $\begin{array}{l}\text { Positive predictive } \\
\text { value }\end{array}$ & 86.83 & 96.87 \\
\hline $\begin{array}{l}\text { Negative predictive } \\
\text { value }\end{array}$ & 81.33 & 76.54 \\
\hline
\end{tabular}

\section{DISCUSSION}

The study showed that when both NST and colour Doppler were abnormal, baby weight and gestation age at birth were low. But the perinatal mortality and neonatal morbidity were high. When both NST and colour Doppler were abnormal it indicates that these foetuses suffer from severe placental insufficiency.

Gomathi V et al conducted study on 90 singleton pregnancies beyond 30 weeks of gestation. They concluded that an abnormal NST following an abnormal Doppler is associated with worst perinatal outcome in patients with severe preeclampsia and foetal growth restriction. In cases of abnormal doppler if prospects of neonatal survival are good it is better to deliver the foetus before NST becomes abnormal. Colour doppler is useful in recognizing foetal compromise earlier than NST, giving a lead time which is important in the management of preterm high risk pregnancies as severe preeclampsia and foetal growth restriction. Even though both tests are complimentary to each other in foetal surveillance of high risk pregnancies, the clinical condition dictates the most appropriate step. ${ }^{4}$

Verma U et al, conducted study on 100 antenatal patients of $>34$ weeks gestation. They categorized the patients into 4 sub-groups according to NST and Doppler findings. They found that in high risk group 36\% had normal NST while $64 \%$ had abnormal. In control group $82 \%$ had normal NST while $18 \%$ show abnormal NST. In doppler study 52\% were having abnormal doppler findings suggestive of foetal hypoxia and $48 \%$ cases had normal doppler in high risk group. In control group $96 \%$ had normal doppler findings. They concluded that doppler is useful in recognizing foetal compromise earlier than NST. It gives a lead time which is important in management of preterm high risk pregnancies. Doppler depicts chronic hypoxic changes while NST can detect acute events in presence or absence of chronic hypoxia. An abnormal NST following an abnormal Doppler is associated with worst perinatal outcome. NST still holds its importance because of its ease of use, low cost and minimal time required. On the other hand doppler requires sophisticated instruments, operative skills and experience. ${ }^{5}$

Anand $\mathrm{R}$ et al found that group $\mathrm{D}$ with both non-reactive NST and abnormal doppler, perinatal outcome was worst in terms of low birth weight, APGAR $<7$, NICU admission and high perinatal mortality. Perinatal outcome was better in group $\mathrm{C}$ suggesting that foetus was significantly more compromised when both tests were abnormal as compared to only doppler abnormal. Similarly when group B was compared with group C it was found that perinatal outcome was better in group $\mathrm{C}$ which showed that doppler predicts foetal compromise earlier as compared to NST which becomes abnormal later in relatively more compromised fetus. ${ }^{6}$

\section{CONCLUSION}

The use of both NST and colour doppler in antepartum foetal surveillance has decreased perinatal morbidity and mortality and the need for extended neonatal intensive care, as they help determine when a hostile intrauterine environment precludes continuing pregnancy.

Even though both tests are complimentary to each other in foetal surveillance of high risk pregnancies, the clinical condition dictates the appropriate test. Using both NST and colour doppler for the antenatal evaluation of high risk pregnancies enables obstetricians to achieve better evaluation of the foetus at risk for better perinatal outcome.

Funding: No funding sources

Conflict of interest: None declared

Ethical approval: The study was approved by the Institutional Ethics Committee

\section{REFERENCES}

1. Arias F, Daftary SN, Bhide AG. Practical guide to high-risk pregnancy and delivery: a South Asian perspective. 2011;3:16-29.

2. Patrick J, Carmichael L, Chess L. Accelerations of the human foetal heart rate at 38-40 weeks gestation age. Am J Obstet Gynecol. 1984;148(1):35-41.

3. Maulik D, Lysikiewicz A. Umbilical arterial doppler sonography for foetal surveillance in pregnancies complicated by pre-gestational diabetes mellitus. J Matern Fetal Neonat Med. 2002;12(6):417-22.

4. Gomathi V, Mythili K. Colour doppler versus NST in predicting perinatal outcome in severe preeclampsia and foetal growth restriction. J Evolution Medical Dental Sci. 2015;4(39):6804-10.

5. Verma U, Garg R. Comparative study of foetal colour doppler versus non-stress test as a predictor of 
perinatal outcome in high risk pregnancy. Obstet Gynecol Int J. 2015;2(6):00065.

6. Anand RT, Chauhan A. Relationship of the findings of colour doppler and non-stress test with the perinatal outcome among the cases of intrauterine growth restriction. MVP Journal Med Sci. 2016;3(2):115-7.
Cite this article as: Paliwal $\mathrm{S}$, Shaheen R, Paliwal S, Parakh P, Yadav K, Chaudhary G, Jalandhara J. Comparative role of non-stress test and colour doppler in high risk pregnancy predicted by placental histopathology and foetal outcome.Int J Reprod Contracept Obstet Gynecol 2017;6:1444-8. 